\title{
Diversity of dinoflagellate symbionts in Red Sea soft corals: mode of symbiont acquisition matters
}

\author{
O. Barneah ${ }^{1, *}$, V. M. Weis ${ }^{2}$, S. Perez ${ }^{2}$, Y. Benayahu ${ }^{1}$ \\ ${ }^{1}$ Department of Zoology, George S. Wise Faculty of Life Sciences, Tel Aviv University, Ramat Aviv, Tel Aviv 69978, Israel \\ ${ }^{2}$ Department of Zoology, Oregon State University, Corvallis, Oregon 97331, USA
}

\begin{abstract}
Symbiotic associations are ubiquitous in terrestrial and marine environments and are of great ecological importance. The onset of a symbiotic relationship differs among associations. Symbionts can be vertically transmitted from host parent to offspring or they can be acquired horizontally from the surrounding environment with each new host generation. Cnidarian-algal symbioses, the subject of our study, exhibit both strategies. We investigated the clade identity of symbionts in soft coral hosts (Eilat, Red Sea) in relation to their hosts' mode of symbiont acquisition. We found for the first time that all hosts using horizontal transmission harbored symbionts belonging to Clade $\mathrm{C}$ while those with vertical transmission uniquely harbored symbionts from Clade A. The latter, capable of coping with a wide array of environmental conditions, evolved to be optimal vertically transmitted symbionts. The limitation of Clade A symbionts to hosts with vertical transmission suggests a coevolution of the hosts and symbionts. Clade $\mathrm{C}$ symbionts, characterized by large sub-clade variability, are found in corals with horizontal transmission and, most probably, each of its genotypes exhibits a more specialized set of physiological capabilities.
\end{abstract}

KEY WORDS: Symbiont acquisition · Octocorals $\cdot$ Zooxanthellae $\cdot$ Red Sea Resale or republication not permitted without written consent of the publisher

\section{INTRODUCTION}

Among the most significant marine mutualisms are those found between members of the phylum Cnidaria, such as corals and anemones, and their photosynthetic dinoflagellate symbionts Symbiodinium spp, (also called zooxanthellae), which together form the trophic and structural foundations of coral reef ecosystems. There is a rich literature on coral systematics and phylogeny, based on skeletal morphology (Veron 1995) and more recently also on molecular markers (Chen et al. 2002). In contrast, classical taxonomic studies of the zooxanthellae are hindered by what seems to be a uniform algal morphology. The advent of molecular tools has resulted in the birth of the field of zooxanthellae molecular phylogenetics and systematics. Zooxanthellae are now known to be taxonomically highly diverse and have been divided into 5 distinct clades (A, B, C, D and $E$ ), based on ribosomal RNA gene sequences and RFLP patterns (Rowan \& Powers 1991a,b, Rowan 1998, LaJeunesse 2001, Toller et al. 2001). These clades rep- resent subgeneric taxonomic levels, and each contains 1 or more subtypes, as revealed by analysis of the internal transcribed spacer regions (LaJeunesse 2001, Savage et al. 2002).

Symbiotic systems, being based on the relationship of 2 different entities have always been subject to the study of specificity (see Douglas 1994). Dealing with Cnidarian-algal symbiosis, this subject represents a complex case study, which can be attributed to: (1) the taxonomy of the symbionts being still under investigation; (2) dual mechanism of symbiont acquisitionsource of symbionts varies with host taxon; (3) the fact that there are hundreds of host species and unknown numbers of symbiont species. There are different aspects (biotic and abiotic) to the study of specificity and many of them have already been dealt with (see Baker 2003). The use of finer resolution molecular tools and the screening of a wide array of cnidarian hosts over a wide biogeographic range (LaJeunesse 2002, LaJeunesse et al. 2003) is doubtless of great importance to our understanding of specificity in this sym- 
biosis. Another important factor to consider in studies of host-symbiont specificity is the mode of symbiont acquisition by the host (Rowan 1998).

The onset of symbiosis can occur at a variety of host life history stages, depending on the host species. Symbionts can be transmitted horizontally, where the host's sexual progeny acquire symbionts from the surrounding environment, or vertically, being passed directly from host parent to offspring (Trench 1987, Douglas 1994). Horizontal transmission offers the host the opportunity to recombine with different algal types that are differentially adapted to the existing environmental conditions. There is a risk, however, that a host may fail to establish a partnership, leaving it with severely reduced fitness. In contrast, vertical transmission guarantees that a host is provided with a complement of symbionts. It is still unclear how the mode of symbiont acquisition influences zooxanthellae diversity within a host (Muller-Parker \& D'Elia 1997, Rowan 1998).

Soft corals (Octocorallia, Alcyonacea) are a significant component of the coral reefs of the northern Red Sea (Benayahu 1985). The life histories and reproductive biology of many Red Sea soft corals are known, as well as the different modes of algal acquisition by the different species (Benayahu 1997). To date, most studies examining zooxanthellae diversity in the Octocorallia have focused on seawhips (family: Plexauridae) (Coffroth et al. 2001, Santos et al. 2001, LaJeunesse 2002), while no comprehensive data exist on soft coral symbionts. Furthermore, data concerning zooxanthellae diversity in Red Sea cnidarians are anecdotal (Goulet \& Coffroth 1997, Carlos et al. 1999, LaJeunesse 2001). We compared symbionts found in hosts belonging to the 3 most common soft coral families, which exhibit different modes of symbiont acquisition, using restriction fragment length polymorphism (RFLP) of the 18S rRNA gene (Rowan \& Powers 1991b). Our results show a novel pattern of symbionts' clade segregation corresponding to the host's mode of symbiont acquisition.

\section{MATERIALS AND METHODS}

Collection and identification. Of the 3 families Alcyoniidae, Nephteidae and Xeniidae, 19 soft coral species were investigated in this study (see Table 1). Samples were collected by SCUBA diving from sites along Eilat's reefs (northern Red Sea) during August 2001. From each species, 3 colonies were frozen and stored at $-20^{\circ} \mathrm{C}$ until further analysis. Before freezing, a portion of each sample was preserved in $70 \%$ ethanol for species identification using the reference collection of the Zoological Museum of Tel Aviv University. When present, mature oocytes were examined under a compound microscope to detect the presence of zooxanthellae, in cases where no previous data were available.

Extraction of DNA. Samples were thawed, transferred to microfuge tubes, and ground with a small plastic pestle in filtered seawater. Homogenates were then centrifuged for $2 \mathrm{~min}$ at $2000 \mathrm{rpm}(350 \times g)$ to pellet the algae. Animal supernatant was removed and discarded and the algal pellet was resuspended in DNA extraction Buffer (4M NaCl, 50mM EDTA, $\mathrm{pH}=$ 8.0). After further centrifugation, the pellet was resuspended in CTAB buffer and incubated for $2 \mathrm{~h}$ at $50^{\circ} \mathrm{C}$ together with Proteinase K. The DNA extraction procedure was continued using a DNAeasy Tissue Kit (QIAGEN).

PCR amplification and restriction fragment length polymorphism (RFLP) analysis. The 18S rRNA gene was amplified from symbiotic dinoflagellates using the primers rRNA-F2 5'-TATTTGATGGTYRCTGCTAC-3' and rRNA-R2 5'-CRAATWATTCACCGGATCAC-3', similar to those used by Rowan \& Powers (1991a). Amplifications were performed using a DNA thermal cycler (UNO II, BIOMETRA) under the following conditions: $94^{\circ} \mathrm{C}$ for $45 \mathrm{~s}, 54^{\circ} \mathrm{C}$ for $45 \mathrm{~s}$ and $72^{\circ} \mathrm{C}$ for $2 \mathrm{~min}$ (31 cycles). RFLP analysis was performed using restriction digests with Taq I (MBI Fermentas) and Dpn II (BioLabs) restriction enzymes for $2.5 \mathrm{~h}$ at 65 and $37^{\circ} \mathrm{C}$, respectively. Digestion products were separated by electrophoresis in $2 \% 0.5 \mathrm{X}$ Tris-Borate (TBE) agarose gels to generate RFLP patterns, which were compared to the literature to assign each sample to one of the established Symbiodinium 18S-rDNA RFLP clades (Rowan \& Powers 1991a,b, Banaszak et al. 2000).

DNA sequencing. PCR products were cloned into pDrive cloning vector with QIAGEN EZ competent cells as a host, using QIAGEN PCR Cloning Plus kit according to the manufacturer's instructions. Plasmid DNA from individual colonies was purified using QIAprep Spin Miniprep kit (QIAGEN). The plasmid DNA was sequenced using the ABI PRISM BigDye Terminators v 3.0 Cycle Sequencing Kit (Applied Biosystems). Due to the large size of the insert (1600 bp), each sample was sequenced from both sides using T7 and SP6 primers. Partial sequences of symbiont genotypes derived in this study were submitted to GenBank. Accession numbers for sequences of symbionts isolated from the corals Litophyton arboreum, Rhytisma fulvum fulvum, Nephthea sp., Cladiella tuberculoides, Sinularia querciformis, Sarcophyton glaucum, Xenia farauensis, Paralemnalia eburnean, Stereonephthya cundabiluensis and Anthelia glauca are AY525018-27 respectively. The symbiont isolated from Heteroxenia fuscescens is available under the accession number AY488089. 
In order to sequence the second genotype of symbionts, observed in 5 of the Alcyoniid corals, the PCR product of the coral Sarcophyton glaucum was cloned as described above. The transformed bacteria colonies were picked and used as template in a PCR reaction, using the vector primers. PCR products were run on an agarose gel to insure an insert in the right size. Subsequently, the products were digested with Taq I restriction enzyme. Three PCR products, which showed the distinct band pattern, were sequenced as described above.

Phylogenetic analysis. Fragments of ssrRNA sequences were obtained for the $3^{\prime}$ and $5^{\prime}$ ends. These sequences were joined to form a partial composite sequence for each species. Sequences were aligned using the multiple sequence alignment program CLUSTAL-XW (Thompson et al. 1997). The following reference sequences taken from GenBank for the 18S rRNA gene were also included in the alignment: Symbiodinium sp. GenBank accession number AF238256 (Clade A); Symbiodinium sp. GenBank accession number AB016594 (Clade C); and Gymnodinium simplex GenBank accession number GSU41086 (Outgroup). The alignment was checked and adjusted by eye using the sequence manipulation program MacVector. Only the aligned sequence portions which were represented by all sequences included were used in the phylogenetic analysis. This was performed by excluding non-overlapping characters using the mask tool of MacVector. Gaps in the alignments were treated as a fifth character. A total of 1114 characters were included in the mask. The final alignment with the applied mask was converted to a Nexus format file and used with the phylogenetic analysis program PAUP* 4.0. The phylogenetic reconstruction was performed with the Neighbor Joining (NJ) applying the Kimura 2-parameter model, as well as Maximum Parsimony method. The sequence from Gymnodinium simplex (GenBank accession number GSU41086) was used as the outgroup. Bootstrapping was performed using 1000 replications and a Bootstrap consensus tree was constructed using the $50 \%$ majority rule.

\section{RESULTS}

Among the 19 soft coral species studied (Table 1), 16 contained zooxanthellae belonging to Clade $\mathrm{C}$, whereas 3 species contained zooxanthellae from Clade A (Figs. 1 \& 2). All species harboring Clade $C$ algae acquire their symbionts horizontally from the environment, while the species harboring Clade A algae acquire theirs directly from the parent at the oocyte stage. The RFLP patterns of 5 of the alcyoniid corals revealed an additional faint band 720 bp in size (Fig 1, Lanes 9 to 13). This band is indicative of the presence of another symbiont genotype. Cloning and sequencing of this genotype (isolated from Sarcophyton glaucum) revealed that it belongs to Clade C.

Table 1. List of soft corals examined, their modes of reproduction and developmental stage during which symbionts are acquired.

${ }^{*}$ Partial sequence of $18 \mathrm{~S}$ rRNA gene of zooxanthellae is available. nd = no data

\begin{tabular}{|c|c|c|c|c|c|}
\hline Species & $\begin{array}{l}\text { Mode of } \\
\text { reproduction }\end{array}$ & $\begin{array}{l}\text { Zooxanthellae } \\
\text { in oocytes }\end{array}$ & $\begin{array}{l}\text { Stage of } \\
\text { acquisition }\end{array}$ & Source & Clade \\
\hline \multicolumn{6}{|l|}{ Alcyoniidae } \\
\hline Cladiella pachyclados & Spawning & No & Primary polyp & This study & $\mathrm{C}$ \\
\hline Cladiella tuberculoides* & nd & nd & nd & & $\mathrm{C}$ \\
\hline Rhytisma fulvum fulvum* & urface brooding & No & Primary polyp & Benayahu \& Loya (1983) & $\mathrm{C}$ \\
\hline Sarcophyton glaucum* ${ }^{*}$ & Spawning & No & Primary polyp & Benayahu \& Loya (1986) & $\mathrm{C}$ \\
\hline Sarcophyton trocheliophorum & Spawning & No & Primary polyp & Shinkarenko (1981); this study & $\mathrm{C}$ \\
\hline Sinularia gardineri & nd & No & nd & This study & $\mathrm{C}$ \\
\hline Sinularia leptoclados & Spawning & No & Primary polyp & Benayahu et al. (1990) & $\mathrm{C}$ \\
\hline Sinularia polydactyla & Spawning & No & Primary polyp & Alino \& Coll (1989) & $\mathrm{C}$ \\
\hline Sinularia querciformis* & nd & No & nd & This study & $\mathrm{C}$ \\
\hline \multicolumn{6}{|l|}{ Xeniidae } \\
\hline Anthelia glauca* & aryngeal brooding & No & Embryo & Kruger \& Schleyer (1998) & $\mathrm{C}$ \\
\hline Heteroxenia fuscescens ${ }^{*}$ & Brooding & No & Primary polyp & Benayahu (1991) & $\mathrm{C}$ \\
\hline Xenia farauensis ${ }^{*}$ & Brooding & No & Embryo & Benayahu \& Loya (1984); this study & $\mathrm{C}$ \\
\hline Xenia macrospiculata & Brooding & No & Embryo & Benayahu et al. (1992) & $\mathrm{C}$ \\
\hline Xenia umbellata & Brooding & No & Embryo & Benayahu (1991) & $\mathrm{C}$ \\
\hline \multicolumn{6}{|l|}{ Nephtheidae } \\
\hline Litophyton arboreum* & Brooding & Yes & Oocyte & Benayahu et al. (1992) & A \\
\hline Nephthea sp. ${ }^{*}$ & Brooding & Yes & Oocyte & Benayahu (1997), Lutzky (1997) & $\mathrm{A}$ \\
\hline Paralemnalia eburnea* & nd & nd & nd & & $\mathrm{C}$ \\
\hline Paralemnalia thyrsoides & Brooding & No & Primary polyp & Benayahu (1997); this study & $\mathrm{C}$ \\
\hline Stereonephthya cundabiluensis* & * Brooding & Yes & Oocyte & Benayahu (1997); this study & A \\
\hline
\end{tabular}




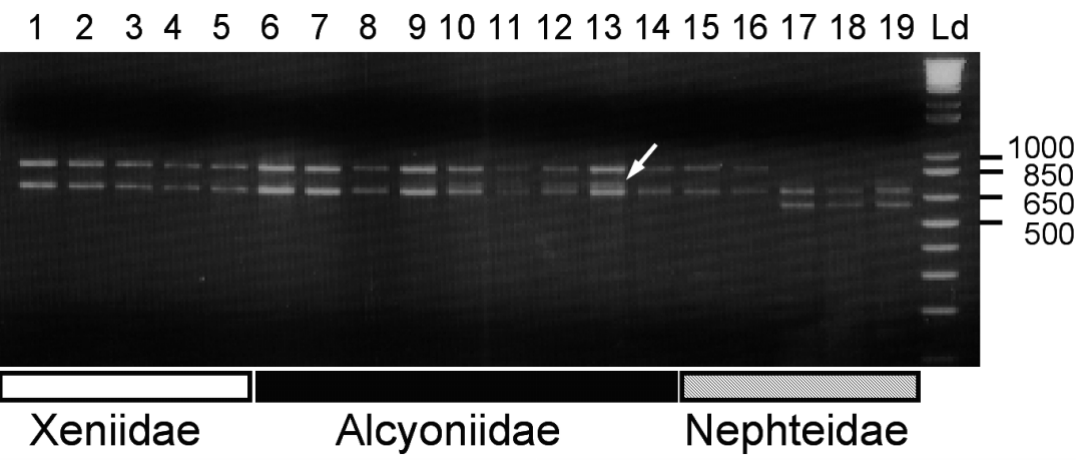

Fig. 1. Taq I RFLP analysis of ss-RNA encoding DNA from zooxanthellae of different Red Sea soft corals. Lane 1 Anthelia glauca, Lane 2 Heteroxenia fuscescens, Lane 3 Xenia farauensis, Lane 4 Xenia macrospiculata, Lane 5 Xenia umbellata, Lane 6 Cladiella tuberculoides, Lane 7 Cladiella pachyclados, Lane 8 Sinularia querciformis, Lane 9 Sinularia polydactyla, Lane 10 Sinularia leptoclados, Lane 11 Sinularia gardineri, Lane 12 Sarcophyton glaucum, Lane 13 Sarcophyton trocheliophorum, Lane 14 Rhytisma fulvum fulvum, Lane 15 Paralemnalia eburnea, Lane 16 Paralemnalia thyrsoides, Lane 17 Litophyton arboreum, Lane 18 Nephthea sp., Lane 19 Stereonphthya cundabiluensis, Lane Ld 1kb Plus DNA ladder (GibcoBRL). White arrow indicates the $720 \mathrm{bp}$ band

The mode of sexual reproduction in soft corals (families Alcyoniidae, Nephteidae and Xeneiidae) and features such as the onset of symbiosis during development and presence or absence of zooxanthellae in oocytes exhibit a high degree of consistency within genera (Benayahu 1997). Thus, in the few cases in our study where no data are provided for a given species in Table 1, it is likely that the mode of reproduction, presence/absence of zooxanthellae in oocytes and stage of algal acquisition follow the respective patterns of the congeners.

All the Alcyoniidae corals studied, including spawners and a surface brooder (Table 1), acquired algae from the environment during their primary polyp stage (Table 1) (Benayahu 1997) and possessed zooxanthellae belonging to Clade $\mathrm{C}$ (Fig. 1, Lanes 1 to 8) or a combination of 2 genotypes of Clade C (Fig. 1, Lanes 9 to 13). Similarly, all Xeniidae examined possessed Clade C zooxanthellae. The latter display a diversity of brooding mechanisms and differ in the developmental stage during which symbionts are acquired. Planulae of Heteroxenia fuscescens lack zooxanthellae when released and acquire symbionts soon after metamorphosis (Benayahu et al. 1989a,b). In Anthelia glauca, zooxanthellae appear in the embryos, which are brooded within the pharyngeal cavity of the polyps (Benayahu \& Schleyer 1998, Kruger et al. 1998). Planulae of Xenia species develop inside invaginated brooding chambers lined with ectoderm, which are open to the environment and contain zooxanthellae that are phagocytosed by the brood (Achituv et al. 1992). Hence, planulae of A. glauca and

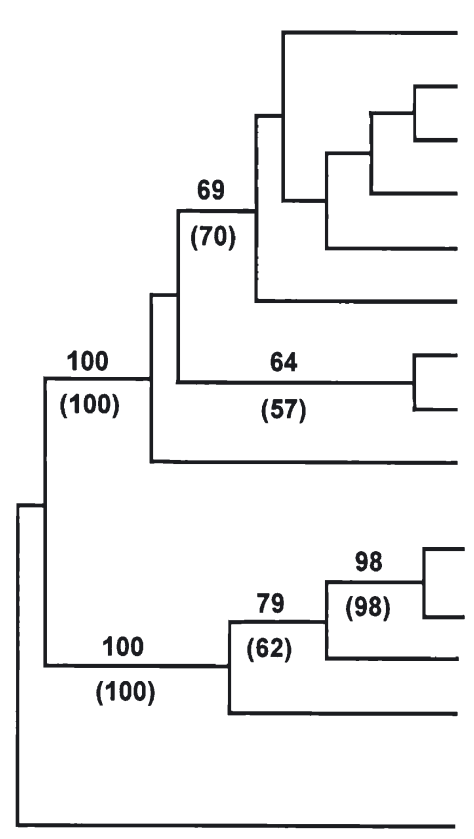

S. sp (Anthelia glauca)

S. sp. (Heteroxenia fuscescens)

S. sp (Xenia farauensis)

S. sp (Paralemnalia eburnea)

S. sp. (Sarcophyton glaucum)

S. sp. (Sinularia querciformis)

S. sp. (Cladiella tuberculoides)

S. sp. (Rhytisma fulvum fulvum)

Symbiodinium sp.

(GenBank accession \#: AB016594)

S. sp. (Litophyton arboreum)

S. sp. (Nephthea sp.)

S. sp. (Stereonephthya cundabiluensis)

Symbiodinium sp.

(GenBank accession \#: AF238256)

Gymnodinium simplex

(GenBank accession \#: U41086)
Fig. 2. Phylogenetic reconstruction of Symbiodinium spp. from different soft coral host species using partial sequences of $18 \mathrm{~s}$ rRNA gene. Trees constructed based on both the NJ and MP methods had the same topology. Names in parentheses indicate host species from which algal (symbiont) sequences were obtained. Gymnodinium simplex was used as the outgroup. Bootstrap consistency values $>50$ based on 1000 replicates are shown above the branches for the NJ analysis and under the branches in parentheses for the MP analysis 
Xenia species acquire their symbionts horizontally prior to release. Thus, all the studied alcyoniid and xeniid soft corals, despite variations in the mode of reproduction and stage of acquisition (see also Table 1), contain symbiotic algae belonging to Clade $\mathrm{C}$.

It is in the Nephtheidae that the different modes of symbiont acquisition were found to correlate with the symbiont clade found in adults. Although all 5 nephtheid species studied are brooders, the 2 in the genus Paralemnalia ( $P$. thyrsoides and $P$. eburnea), release azooxanthellate planulae (Table 1) that must acquire symbionts horizontally. Like the above-mentioned xeniid and alcyoniid species with horizontal transmission, these too contained Clade $\mathrm{C}$ zooxanthellae. In contrast, Litophyton arboreum, Nephthea sp. and Stereonephthya cundabiluensis have vertical symbiont acquisition, where zooxanthellae are directly transmitted to their sexual progeny at the oocyte stage (Table 1). These 3 species uniquely harbored Clade A zooxanthellae.

\section{DISCUSSION}

Symbiotic associations between Cnidarian hosts and their symbiotic algae exhibit 2 possible modes of symbiont acquisition: vertical and horizontal. We examined multiple host species in one location and herein provide, for the first time, perspective on the mode of symbiont acquisition and its relation to clade specificity in a variety of soft coral hosts. Previous studies addressing this subject in stony corals have examined a restricted number of species over a broad biogeographic scale (Hidaka \& Hirose 2000, Loh et al. 2001, Rodriguez-Lanetty et al. 2001). Recently, Van Oppen (2004) compared the diversity of symbionts in 25 Montipora species (vertical transmission) and Acropora species (horizontal transmission) in Indonesia and the central Great Barrier Reef, Australia. They found that the mode of symbiont acquisition does not affect symbiont diversity (i.e. number of symbiont types within a host) within acroporid corals.

The Gulf of Eilat, situated at the northernmost limit of coral reefs distribution, is characterized by extreme environmental conditions such as catastrophic low tides, elevated temperatures and high irradiance (Loya 1986, Achituv \& Dubinsky 1990). However, no bleaching events have been reported from this area (Pilcher \& Alsuhaibany 2000). Our data indicate that hosts harboring either Clade A or Clade C symbionts co-occur in the same habitats. For example, Litophyton arboreum (Clade A) and Rhytisma fulvum fulvum (Clade C) form monospecific carpets on Eilat's reef flats (Benayahu \& Loya 1977). Furthermore, molecular analysis of zooxanthellae from Heteroxenia, Sinularia,
Rhytisma, Stereonephtya and Litophyton, sampled over a depth gradient (1 to $20 \mathrm{~m}$ ), reveals persistence in clade specificity with depth within a host (O. Barneah unpubl. data). Therefore, the distribution of symbiont clades in Eilat's soft corals negates the correlation between symbiont clade and depth demonstrated in Caribbean reefs (Rowan \& Knowlton 1995, Rowan et al. 1997, LaJeunesse 2001, Toller et al. 2001).

Symbionts belonging to Clade A were only found in hosts that vertically transmit their symbionts. There is evidence from studies performed in the Caribbean that Clade A zooxanthellae are shallow-water specialists (Toller et al. 2001, LaJeunesse 2002), and are relatively stress tolerant or 'weedy' (Rowan 1998). It has also been shown that Clade A zooxanthellae are widely tolerant to temperature change (Kinzie et al. 2001) and are the only clade capable of synthesizing mycosporine-like amino acids (MAAs) (Banaszak et al. 2000). Together, these studies suggest that Clade $A$ algae may be well adapted to cope with Eilat's environmental conditions. We suggest that Clade A symbionts, evolved to be optimal vertically transmitted symbionts, that did not fail their host and thus persisted as faithful symbionts for generations. It should be pointed out that data are lacking concerning the survival of Clade A symbionts in the free living state. For example, they might be very successful within the coral tissues but outcompeted by different algal clades while in the water column. The limitation of Clade A symbionts to hosts with vertical transmission suggests a coevolution of the hosts and symbionts. Data on the phylogeny of Red Sea soft corals that could be overlaid onto the phylogeny of the symbionts will yield further information on how the observed specificity pattern arose. Were Clade A algae 'captured' by a single nephtheid ancestor that gave rise to the 3 vertically transmitting genera, or did this event occur a multiple of times within the family? No congruence was found between Montipora host and symbiont phylogenies, a fact that might be attributed to occasional lateral transfer of zooxanthellae between species, which might have occurred as a result of interspecific hybridization arising during mass spawning events (Van Oppen et al. 2004). We anticipate a different result in the 3 nephtheid hosts harboring Clade A zooxanthellae. These corals are brooders, from a region characterized by temporal reproductive isolation rather than by mass spawning events (Shlesinger \& Loya 1985), representing the most conservative scenario among cnidarians, in terms of vertical transmission.

Clade C symbionts, characterized by large sub-clade variability (Fig. 2), are found in corals with horizontal transmission and, most probably, each of this clade's genotypes exhibits a more specialized set of physiological capabilities. Recently, LaJeunesse et al. (2003) 
found that the majority of endosymbiotic dinoflagellates in cnidarians in the Great Barrier Reef (Australia) belong to Clade $\mathrm{C}$, which is composed of closely related, yet ecologically and physiologically distinct, types. The observed combination of 2 different genotypes of Clade $\mathrm{C}$ in 5 species of alcyoniid soft corals further highlights the flexibility of an open system of symbiont acquisition. We hypothesize that free-living stages of Clade $\mathrm{C}$ symbionts are prevalent in the reef area and are available for acquisition by juvenile stages of soft coral hosts. Future studies examining distribution and availability of symbionts in the open water and physiological plasticity of different symbionts strains are needed to test these hypotheses.

Based on our results from soft corals and on the recent literature (LaJeunesse et al. 2003, Van Oppen 2004a) in stony corals (Montipora and Porites respectively), we hypothesize that corals which vertically transmit their symbionts will tend to have genetically distinct symbionts, which differ from those found in corals with horizontal transmission. In our study, the distinctive feature is symbiont clade, while in Montipora and Porites, the symbionts were found to belong to a distinct sub-clade. Whether the symbionts belonging to Clade A (from the 3 studied nephtheid corals) represent one type or 3 distinct, yet similar, types is yet to be determined.

Vertical transmission is relatively rare among cnidarians (Trench 1987). Coral hosts with vertical transmission of symbionts are assumed to represent a scenario in which a certain ancestral symbiont was 'trapped' and evolved within host tissues. It is likely that these holobionts were exposed to changing environmental conditions during their evolution and their survival therefore indicates their resilience. Is it possible that corals which vertically transmit their symbionts are more resistant to environmental change? Are coral hosts with vertical transmission less susceptible to bleaching? There are some data in support of these hypotheses. Among a variety of Great BarrierReef stony corals, 2 of the most bleaching resistant species were Montipora digitata and Porites cylindrica, which both transmit symbionts vertically and associate with the unique Symbiodinium strain C15 (LaJeunesse et al. 2003). A combined comparative approach of sampling symbionts from hosts with vertical versus horizontal transmission, and analysis of their physiological capabilities, can answer these questions.

New data are continually emerging on zooxanthellae systematics and the relation thereof to hostsymbiont specificity. Our study, by examining the correlation between symbiont taxon and the mode of symbiont acquisition by soft coral hosts, describes another layer of complexity in this symbiotic relationship. The pattern of clade distribution which we describe is exceptional, and raises many questions to be addressed on a global scale.

Looking at other symbiotic systems, such as the aphid-bacteria, in which the phylogeny of symbionts parallels their hosts (Douglas 1994), it is very clear that we are uncovering a multidimensional concept of specificity, rather then a 2-dimensional one.

Acknowledgements. We acknowledge E. Rosenberg, A. Post, O. Mokady, D. Graur, and T. Dagan for critical comments on the manuscript. We thank H. Nelson, Y. Nevo and W. Reynolds for valuable assistance in the laboratory, V. Wexsler for graphical assistance and N. Paz for editorial assistance. We thank the staff of the Interuniversity Institute of Eilat for their kind hospitality and facilities. We thank the anonymous reviewers who contributed to the improvement of this manuscript. This research was supported by grant 1998458 from the United States-Israel Binational Science Foundation (BSF) Jerusalem Israel. O.B. was supported by a fellowship granted by Tobias Landau Foundation. Field collection of animals complied with a permit issued by the Israel Nature and National Parks Protection Authority.

\section{LITERATURE CITED}

Achituv Y, Dubinsky Z (1990) Evolution and zoogeography of coral reefs. In: Dubinsky Z (ed) Ecosystems of the world: Coral reefs. Elsevier Science Publishers, Amsterdam, p 1-9

Achituv Y, Benayahu Y, Hanania J (1992) Planulae brooding and acquisition of zooxanthellae in Xenia macrospiculata (Cnidaria: Octocorallia). Helgol Meeresunters 46:301-310

Alino PM, Coll JC (1989) Observations on synchronized mass spawning and postsettlement activity of the octocorals on the Great Barrier Reef, Australia: biological aspects. Bull Mar Sci 45:697-707

Baker AC (2003) Flexibility and specificity in coral-algal symbiosis: Diversity, ecology, and biogeography of Symbiodinium. Annu Rev Ecol Syst 34:661-689

Banaszak AT, LaJeunesse TC, Trench RK (2000) The synthesis of mycosporin-like amino acids (MAAs) by cultured symbiotic dinoflagellates. J Exp Mar Biol Ecol 249:219-233

Benayahu Y (1985) Faunistic composition and patterns in the distribution of soft corals (Octocorallia: Alcyonacea) along the coral reefs of Sinai Peninsula. In: Gabrie C et al. (eds) Proc 5th Int Coral Reef Congr. Antenne Museum-EPHE, Moorea, French Polynesia, 6:255-260

Benayahu Y (1991) Reproduction and developmental pathways of Red Sea Xeniidae (Octocorallia, Alcyonacea). Hydrobiologia 216/217:125-130

Benayahu Y (1997) Developmental episodes in reef soft corals: Ecological and cellular determinants. Proc 8th Int Coral Reef Symp. Smithsonian Tropical Research Institute, Balboa, Panama, 2:1213-1218

Benayahu Y, Loya Y (1977) Space partitioning by stony corals soft corals and benthic algae on the coral reefs of the northern Gulf of Eilat (Red Sea). Helgol Wiss Meeresunters 30:362-382

Benayahu Y, Loya Y (1983) Surface brooding in the Red-Sea soft coral Parerythropodium f. fulvum. Biol Bull 165:353-369

Benayahu Y, Loya Y (1984) Life history studies on the soft coral Xenia microspiculata Gohar, 1940 II. Planulae shedding and post larval development. Biol Bull 166:44-53

Benayahu Y, Loya Y (1986) Sexual reproduction of a soft coral: synchronous and brief annual spawning of Sarcophyton glaucum (Quoy \& Gaimard, 1833). Biol Bull 170:32-42 
Benayahu Y, Schleyer MH (1998) Reproduction in Anthelia glauca (Octocorallia: Xeniidae) II. Transmission of algal symbionts during planular brooding. Mar Biol 131:433-442

Benayahu Y, Achituv Y, Berner T (1989a) Metamorphosis of an octocoral primary polyp and its infection by algal symbiosis. Symbiosis 7:159-169

Benayahu Y, Berner T, Achituv Y (1989b) Development of planulae within a mesogleal coat in the soft coral Heteroxenia fuscescens. Mar Biol 100:203-210

Benayahu Y, Weil D, Kleinman M (1990) Radiation of broadcasting and brooding patterns in coral reef alcyonaceans. In: Hoshi M, Yamashita O (eds) Adv Invertebr Reprod 5: 323-328

Benayahu Y, Weil D, Malik Z (1992) Entry of algal symbionts into oocytes of the coral Litophyton arboreum. Tissue Cell 24(4):473-482

Carlos AA, Baillie BK, Kawachi M, Maruyama T (1999) Phylogenetic position of Symbiodinium (Dinophyceae) isolates from tridacnids (Bivalvia), a sponge (Porifera), a soft coral (Anthozoa), and a free-living strain. J Phycol 35: 1054-1062

Chen CA, Wallace CC, Wolstenholme J (2002) Analysis of the mitochondrial 12S rRNA gene supports a 2-clade hypothesis of the evolutionary history of scleractinian corals. Mol Phylogenet Evol 23 (2):137-149

Coffroth MA, Santos SR, Goulet TL (2001) Early ontogenetic expression of specificity in a cnidarian-algal symbiosis. Mar Ecol Prog Ser 222:85-96

Douglas AE (1994) Symbiotic Interactions. Oxford University Press, New York

Goulet TL, Coffroth MA (1997) Geographic distribution of zooxanthellae genotypes in Octocorals. Am Zool 37(5):73A

Hidaka M, Hirose M (2000) A phylogenetic comparison of zooxanthellae from reef corals with different modes of symbiont acquisition. 9th Int Coral Reef Symp, Bali (Abstract only)

Kinzie R, Takayama AM, Santos SR, Coffroth MA (2001) The adaptive bleaching hypothesis: Experimental tests of critical assumptions. Biol Bull 200(1):51-58

Kruger A, Schleyer MH, Benayahu Y (1998) Reproduction in Anthelia glauca (Octocorallia: Xeniidae). I. Gametogenesis and larval brooding. Mar Biol 131:423-432

LaJeunesse TC (2001) Investigating the biodiversity, ecology, and phylogeny of endosymbiotic dinoflagellates in the genus Symbiodinium using the ITS region: in search of a 'species' level marker. J Phycol 37:866-880

LaJeunesse TC (2002) Diversity and community structure of symbiotic dinoflagellates from Caribbean coral reefs. Mar Biol 141:387-400

LaJeunesse TC, Loh WKW, van Woesik R, Hoegh-Guldberg O, Schmidt GW, Fitt WK (2003) Low symbiont diversity in southern Great Barrier Reef corals, relative to those of the Caribbean. Limnol Oceanogr 48(5):2046-2054

Loh WKW, Toha L, Dee C, Hoegh-Guldberg O (2001) Genetic variability of the symbiotic dinoflagellates from the wide ranging coral species Seriatopora hysterix and Acropora longicyathus in the Indo-West Pacific. Mar Ecol Prog Ser 222:97-107

Loya Y (1986) Changes in a Red Sea coral community structure: a long-term case history study. In: Woodwell GM (ed) The earth in transition: patterns and processes of biotic impoverishment. Cambridge University Press, Cambridge Lutzky S (1997) Reproductive strategies of 2 soft coral species:

Editorial responsibility: Charles Birkeland (Contributing Editor), Honolulu, Hawaii, USA
Scleronephthya corymbosa and Nephtea sp. MS thesis, Tel-Aviv University, Tel Aviv

Muller-Parker G, D'Elia CF (1997) Interactions between corals and their symbiotic algae. In: Birkeland $C$ (ed) Life and death of coral reefs. Chapman \& Hall, New York, p 96-113

Pilcher N, Alsuhaibany A (2000) regional status of coral reefs in the Red Sea and the Gulf of Aden. In: Wilkinson C (ed) Status of coral reefs of the world: 2000. Australian Institute of Marine Science, 2000, Dampier, p 35-64

Rodriguez-Lanetty M, Loh WKW, Carter D, Hoegh-Guldberg O (2001) Latitudinal variability in symbiont specificity within the widespread scleractinian coral Plesiastrea versipora. Mar Biol 138:1175-1181

Rowan R (1998) Diversity and ecology of zooxanthellae on coral reefs. J Phycol 34:407-417

Rowan R, Knowlton K (1995) Intraspecific diversity and ecological zonation in coral-algae symbiosis. Proc Natl Acad Sci USA 92:2850-2853

Rowan R, Powers DA (1991a) Molecular genetics identification of symbiotic dinoflagellates (zooxanthellae). Mar Biol 71:65-73

Rowan R, Powers DA (1991b) A molecular genetic classification of zooxanthellae and the evolution of animal-algal symbioses. Science 251:1348-1351

Rowan R, Knowlton N, Baker A, Jara J (1997) Landscape ecology of algal symbionts creates variation in episodes of coral bleaching. Nature 388(6639):265-269

Santos SR, Taylor DJ, Coffroth MA (2001) Genetic comparisons of freshly isolated versus cultured symbiotic dinoflagellates: implications for extrapolating to the intact symbiosis. J Phycol 37:900-912

Savage AM, Goodson MS, Visram S, Trapido-Rosenthal $\mathrm{H}_{\text {, }}$ Wiedenmann J, Douglas AE (2002) Molecular diversity of symbiotic algae at the latitudinal margins of their distribution: dinoflagellates of the genus Symbiodinium in corals and sea anemones. Mar Ecol Prog Ser 244:17-26

Shinkarenko L (1981) The natural history of five species of octocorals (Alcyonacea) with special reference to reproduction at Heron Island reef, Great Barrier Reef. PhD thesis, University of Brisbane

Shlesinger Y, Loya Y (1985) Coral community reproductive patterns: Red Sea versus the Great Barrier Reef. Science 228:1333-1335

Thompson JD, Gibson TJ, Plewniak F, Jeanmougin F, Higgins DG (1997) The ClustalX windows interface: flexible strategies for multiple sequence alignment aided by quality analysis tools. Nucleic Acids Res 24:4876-4882

Toller WW, Rowan R, Knowlton N (2001) Repopulation of zooxanthellae in the Caribbean corals Montastraea annularis and $M$. faveolata following experimental and disease-associated bleaching. Biol Bull 201:360-373

Trench RK (1987) Dinoflagellates in non-parasitic symbioses. In: Taylor FJR (ed) The biology of dinoflagellates. Blackwell, Oxford, p 530-570

Van Oppen MJH (2004) Mode of zooxanthellae transmission does not affect zooxanthellae diversity in acroporid corals. Mar Biol 144(1):1-7

Van Oppen MJH, Koolmees EM, Veron JEN (2004) Patterns of evolution in the scleractinian coral genus Montipora (Acroporidae). Mar Biol 144(1):9-18

Veron JEN (1995) Corals in space and time: the biogeography and evolution of the Scleractinia. University of New South Wales Press, Sydney

Submitted: July 30, 2003; Accepted: March 29, 2004

Proofs received from author(s): June 21, 2004 